\title{
Genetic diversity trend in Indian rice varieties: an analysis using SSR markers
}

\author{
Nivedita Singh ${ }^{1 \dagger}$, Debjani Roy Choudhury ${ }^{1 \dagger}$, Gunjan Tiwari ${ }^{1}$, Amit Kumar Singh ${ }^{1}$, Sundeep Kumar ${ }^{1}$,
} Kalyani Srinivasan², R. K. Tyagi ${ }^{2}$, A. D. Sharma ${ }^{2}$, N. K. Singh ${ }^{3}$ and Rakesh Singh ${ }^{1^{*}}$ (i)

\begin{abstract}
Background: The knowledge of the extent and pattern of diversity in the crop species is a prerequisite for any crop improvement as it helps breeders in deciding suitable breeding strategies for their future improvement. Rice is the main staple crop in India with the large number of varieties released every year. Studies based on the small set of rice genotypes have reported a loss in genetic diversity especially after green revolution. However, a detailed study of the trend of diversity in Indian rice varieties is lacking. SSR markers have proven to be a marker of choice for studying the genetic diversity. Therefore, the present study was undertaken with the aim to characterize and assess trends of genetic diversity in a large set of Indian rice varieties (released between 1940-2013), conserved in the National Gene Bank of India using SSR markers.

Result: A set of 729 Indian rice varieties were genotyped using 36 HvSSR markers to assess the genetic diversity and genetic relationship. A total of 112 alleles was amplified with an average of 3.11 alleles per locus with mean Polymorphic Information Content (PIC) value of 0.29. Cluster analysis grouped these varieties into two clusters whereas the model based population structure divided them into three populations. AMOVA study based on hierarchical cluster and model based approach showed $3 \%$ and $11 \%$ variation between the populations, respectively. Decadal analysis for gene diversity and PIC showed increasing trend from 1940 to 2005, thereafter values for both the parameters showed decreasing trend between years 2006-2013. In contrast to this, allele number demonstrated increasing trend in these varieties released and notified between 1940 to 1985, it remained nearly constant during 1986 to 2005 and again showed an increasing trend.
\end{abstract}

Conclusion: Our results demonstrated that the Indian rice varieties harbors huge amount of genetic diversity. However, the trait based improvement program in the last decades forced breeders to rely on few parents, which resulted in loss of gene diversity during 2006 to 2013. The present study indicates the need for broadening the genetic base of Indian rice varieties through the use of diverse parents in the current breeding program.

Keywords: Rice, HvSSR markers, Hierarchical analysis, Model based analysis, Decadal analysis, India

Abbreviations: AMOVA, Analysis of molecular variance; HvSSR, Hyper variable simple sequence repeats; IC, Indigenous collection; Na, Number of alleles; NJ, Neighbor joining; PCoA, Principal coordinate analysis; PCR, Polymerase chain reaction; PIC, Polymorphic information content; pop, Population; SSR, Simple sequence repeats

\footnotetext{
* Correspondence: singhnbpgr@yahoo.com

${ }^{\dagger}$ Equal contributors

'Division of Genomic Resources, ICAR-National Bureau of Plant Genetic

Resources, New Delhi 110012 , India

Full list of author information is available at the end of the article
} 


\section{Background}

Rice (Oryza sativa L.) is a staple food crop in India and many parts of the world. In India, it occupies the largest area under cultivation and has maximum share in grain production [3]. India is one of the centers for rice diversity and large diversity has been reported both at interand intra- specific levels [36]. Yield, quality characters and tolerance to biotic and abiotic stresses are major objectives of varietal development [25].

A large number of rice varieties are released and notified every year in India with higher yields, tolerance to biotic and abiotic stresses and to meet the requirement of changing farming systems based on user demands. Different rice varieties of distinct genetic background are a good promise for the future rice crop improvement. This has contributed to a large extent to the major increases in agricultural productivity in the twentieth century [10]. It is generally thought that continuous selection among the crosses of genetically related cultivars has led to a narrowing of the genetic base of the crops on which modern agriculture is based, thus contributing to the genetic erosion of the crop gene pools [33].

A robust and reliable method of fingerprinting is required for identification and purity testing of these varieties [41], as well as to study the genetic relationships among different cultivars [18, 42]. Genetic characterization of crop plants has gained momentum with the advent of PCR based molecular markers. Nowadays, SSR is a marker of choice for molecular characterization as it is co-dominant, distributed throughout the genome, highly reproducible, variable, reliable, easily scorable, abundant and multiallelic in nature [37]. SSR markers have been used by many researchers $[9,17,44]$ for characterization of rice varieties. SSR markers even in less number can give a better genetic diversity spectrum due to their multi allelic and highly polymorphic nature [24].

Recent reports suggest that genetic diversity in crop varieties released over the years fluctuates in successive time periods $[8,48]$. In case of wheat there are reports available which showed an increase [16], decrease [12] as well as constant gene diversity over a period of time $[15,35]$. The similar trend was also reported in rice [23, 47]. Over the last few centuries, rice has faced diversity loss [6] especially, after the green revolution due to replacement of native varieties with high yielding varieties [14]. Despite of a large number of varieties being developed in every year, molecular studies on a small set of rice varieties has revealed narrow genetic base [26, 45].

The present study was undertaken with the aim to assess the trend in genetic diversity of Indian rice varieties released and notified over the period from 1940 to 2013 and to understand the genetic relationship amongst the varieties by employing both hierarchical and model based approach using hyper variable simple sequence repeats (HvSSR) markers.

\section{Results and Discussions}

Our study is the first major effort to analyze the trend of genetic diversity in the large set of Indian rice varieties released over the years. A total of 729 varieties released from the year 1940 to 2013 was analyzed using HvSSR markers. These varieties possessed various agronomical and economically important traits such as tolerance to biotic and abiotic stresses (drought, cold, salinity and lodging), aroma content, grain yield and early maturity etc. (Additional file 1: Table S1).

\section{HvSSR marker based analysis}

Thirty-six HvSSR markers were used to characterize 729 rice varieties. Gene diversity, heterozygosity, major allele frequency and PIC were calculated for all the $36 \mathrm{HvSSR}$ markers. A total of 112 alleles was amplified with an average of 3.11 alleles per locus (Table 1). Similar observations were also reported; 3.02 alleles per locus with SSR markers during characterization of 25 Indian rice hybrids [2] and 3 alleles per locus in a set of 192 Indian rice germplasm characterization [25]. The number of alleles amplified per HvSSR primers varied from 2 to 5 with maximum numbers of alleles (5) being amplified by primers; HvSSR09-11, HvSSR11-21, HvSSR11-58 and HvSSR12-13. A similar number of alleles (2-5) for SSR markers were reported in 141 Basmati rice accessions of North Western Himalaya [37]. The PIC values for HvSSR primers ranged from 0.04 (HvSSR06-16) to 0.58 (HvSSR03-37) with a mean of 0.29. Shah et al. [38] and Pachauri et al. [29] have reported mean PIC values 0.37 and 0.38 , respectively in different sets of rice varieties which were closer to our result. On the other hand, Pal et al. [30] reported mean PIC value 0.40 on a set of basmati and non-basmati varieties and Salgotra et al. [37] have reported mean PIC value 0.40 in a basmati collection of north-western Himalaya, which were little higher than our result. The gene diversity ranged from 0.04 (HvSSR06-16) to 0.66 (HvSSR03-37) with an average of 0.33 . Gene diversity obtained in the present study was quite low as compared to 0.52 [25] and 0.54 [6] reported in rice germplasm lines and varieties, respectively. Heterozygosity varied from 0.92 (HvSSR03-02) to 0.00 (HvSSR05-30) with an average of just 0.15. The low level of heterozygosity has also been reported in other studies on rice $[5,25]$ and this could be attributed to its self pollination behavior. The major allele frequency was also calculated for all $36 \mathrm{HvSSR}$ markers which ranged from 0.37 (HvSSR03-37) to 0.97 (HvSSR06-16) with an average of 0.76 (Table 1). The average major allele frequency in the present study was higher as compared to 
Table 1 List of HvSSR primers used for genotyping of 729 rice varieties along with their chromosomal position, product size, No. of alleles amplified, gene diversity, heterozygosity and PIC value

\begin{tabular}{|c|c|c|c|c|c|c|c|c|c|}
\hline Chr. No. & Primer ID & Size (bp) & Forward primer & Reverse primer & $\begin{array}{l}\text { Major allele } \\
\text { frequency }\end{array}$ & Allele no & $\begin{array}{l}\text { Gene } \\
\text { diversity }\end{array}$ & Heterozygosity & $\mathrm{PIC}$ \\
\hline \multirow[t]{3}{*}{1} & HvSSR01-32 & 250 & AAACTGGAGATGAACTCGAA & GTAACGAACTAGAGCATGGG & 0.9445 & 2.0000 & 0.1048 & 0.0340 & 0.0993 \\
\hline & HvSSR01-41 & 348 & TGAGTGAGACTTGACAGTGC & AGTTAACACCAATGCTGACC & 0.5943 & 3.0000 & 0.5405 & 0.2340 & 0.4638 \\
\hline & HvSSR01-53 & 274 & TGTCGTCCACGTAGTAGGAG & ACACTCCTCCTCTGTTCTCA & 0.8894 & 2.0000 & 0.1968 & 0.0030 & 0.1774 \\
\hline \multirow[t]{3}{*}{2} & HvSSR02-01 & 312 & AAGAGATGAGAAGAGCAATGA & CAACTTAGAGGAAGAAGGAGG & 0.7813 & 2.0000 & 0.3417 & 0.0892 & 0.2834 \\
\hline & HVSSR02-33 & 355 & TAATGCACGCACAACTTTAC & TATAGAATGCTGACTGGGCT & 0.7976 & 2.0000 & 0.3228 & 0.0923 & 0.2707 \\
\hline & HvSSRO2-50 & 195 & TाTCAGGAATCTGATGCTIT & TTAATCAAAGCCCTAACAGC & 0.6579 & 3.0000 & 0.5077 & 0.1445 & 0.4547 \\
\hline \multirow[t]{5}{*}{3} & HvSSR03-02 & 228 & TAGCGGAGTTGGAATAACAC & CTGCACTGCATACCTCATAA & 0.5346 & 4.0000 & 0.5737 & 0.9224 & 0.4922 \\
\hline & HvSSR03-10 & 280 & GTACACAACGTCACAACAGC & ACTGTGGCATATGTTCGATT & 0.7566 & 2.0000 & 0.3683 & 0.1468 & 0.3005 \\
\hline & HvSSR03-19 & 230 & AATTCAGTTCACGCATTCTT & AGCTGTTCGTCTGCATAGTT & 0.8968 & 2.0000 & 0.1851 & 0.0577 & 0.1680 \\
\hline & HvSSR03-37 & 386 & GGAAATCGTCAAGAACGTC & TAATTGTATACCACTCCGCC & 0.3780 & 3.0000 & 0.6610 & 0.3013 & 0.5868 \\
\hline & HvSSR03-54 & 352 & GCCTATCAGGCTATCATCAC & GTGATCGACATTGAGGAGTT & 0.8168 & 2.0000 & 0.2993 & 0.0049 & 0.2545 \\
\hline \multirow[t]{3}{*}{4} & HvSSR04-19 & 265 & TCGTGGAGTATCCTGTATCC & TTATAACTTGGAGCTCAGGC & 0.9127 & 3.0000 & 0.1631 & 0.1041 & 0.1566 \\
\hline & HvSSR04-27 & 318 & ATGGATTAGGCTTGTTGA & ATACTGCGAAGGTGAAGAGA & 0.7150 & 4.0000 & 0.4609 & 0.2629 & 0.4319 \\
\hline & HvSSR04-46 & 179 & GGCGCGCTTATATATGTACT & CGATTGCGTGGTGTAACTAT & 0.7774 & 4.0000 & 0.3712 & 0.1475 & 0.3413 \\
\hline \multirow[t]{3}{*}{5} & HvSSR05-09 & 335 & СTCTCCATCTTGCAATCTTC & TGCATGACTCTATCAACCAG & 0.5331 & 3.0000 & 0.5509 & 0.0768 & 0.4558 \\
\hline & HvSSR05-15 & 275 & CCATGTCAAACGGTTACTIT & GGGAGAAGTGAGAAAGAGGT & 0.9366 & 3.0000 & 0.1205 & 0.0975 & 0.1166 \\
\hline & HvSSR05-30 & 353 & TACGACGGACGATTAAAGTT & GCTAACTCATTCATCTCGCT & 0.7962 & 2.0000 & 0.3245 & 0.0000 & 0.2719 \\
\hline \multirow[t]{3}{*}{6} & HvSSR06-03 & 212 & CTAGGGAATCAGCGGTTAG & GCTCTCTTGTCCTTCTTCTTC & 0.9582 & 3.0000 & 0.0802 & 0.0099 & 0.0771 \\
\hline & HvSSR06-16 & 368 & TCTGAAATGCTGTCATCAAG & GAGCAGAGTAGGACATGAGC & 0.9767 & 2.0000 & 0.0454 & 0.0186 & 0.0444 \\
\hline & HvSSR06-40 & 385 & CTCTTCCGTGGTTAAAGAAA & CACTGGTATGATCTCCGACT & 0.5405 & 3.0000 & 0.5285 & 0.2859 & 0.4232 \\
\hline \multirow[t]{2}{*}{7} & HvSSR07-18 & 343 & GGTGTGTTGTCGAATCTCTC & ATGCCATTGTCCTTACATTC & 0.5436 & 3.0000 & 0.5383 & 0.1317 & 0.4392 \\
\hline & HvSSR07-51 & 341 & CGAGCATGTCTGTCAAGTAA & GTTCGAATGTAATGTTGGCT & 0.8503 & 3.0000 & 0.2645 & 0.0349 & 0.2464 \\
\hline \multirow[t]{2}{*}{8} & HvSSR08-14 & 295 & TCCACTTTACATCGTCACAA & СТACCTCTTAACCGCACATT & 0.5996 & 3.0000 & 0.5401 & 0.0736 & 0.4661 \\
\hline & HvSSR08-19 & 221 & CATCTCTTGAGAAATCTGCC & TGTGCATTTCGTCTTTCATA & 0.4944 & 4.0000 & 0.5183 & 0.1278 & 0.4022 \\
\hline \multirow[t]{3}{*}{9} & HvSSRO9-11 & 366 & TGCAGAATTTCTTCCTTCAT & ACCAGAATCTCCCAAATGTA & 0.7632 & 5.0000 & 0.3981 & 0.0371 & 0.3752 \\
\hline & HvSSR09-26 & 331 & TGGGCATCTGGTACTATCTT & AGCTCATTCCACAGGTTAGA & 0.9594 & 2.0000 & 0.0779 & 0.0056 & 0.0749 \\
\hline & HvSSRO9-55 & 382 & TTACTCCGCATATATCCATGT & ATTTGACACCAAGTTGATCC & 0.5925 & 4.0000 & 0.5090 & 0.7326 & 0.4105 \\
\hline \multirow[t]{3}{*}{10} & HvSSR10-03 & 289 & TCTITCCCAAATTCCAGATA & CATTAGTTGTIGTGGCAGA & 0.9081 & 3.0000 & 0.1711 & 0.0883 & 0.1641 \\
\hline & HvSSR10-13 & 169 & CAGGGAATCAACATCAAAGT & AGCAAGGCAAGTCATCTCTA & 0.5795 & 4.0000 & 0.5292 & 0.4003 & 0.4378 \\
\hline & HvSSR10-34 & 202 & TAGACCGAGGAATTGAAAGA & TTTGGGCTTATTGTCAGTTT & 0.9060 & 4.0000 & 0.1749 & 0.0982 & 0.1681 \\
\hline \multirow[t]{3}{*}{11} & HvSSR11-13 & 285 & TGAAACCACAATGAGTCAAA & GCCCTAAACCCAAATAGAAG & 0.7532 & 2.0000 & 0.3718 & 0.1062 & 0.3027 \\
\hline & HvSSR11-21 & 291 & TACGCTATAACCATGAAGCA & CTCCCGTTATTGTCCTTACA & 0.8305 & 5.0000 & 0.2962 & 0.2161 & 0.2766 \\
\hline & HvSSR11-58 & 371 & ACTGAATCCTTACTGGAGCA & GGAGATAAGCATTTGGAAGA & 0.7881 & 5.0000 & 0.3639 & 0.1607 & 0.3451 \\
\hline \multirow[t]{4}{*}{12} & HvSSR12-01 & 271 & GATTTGCAACACGTACGATA & GATCATCCACTCTGAGCAAT & 0.9203 & 2.0000 & 0.1467 & 0.0986 & 0.1360 \\
\hline & HVSSR12-13 & 388 & ACCTTAGGGCTGAGTTCTIT & TTAGGCTTGTCTCTTCCTCA & 0.9048 & 5.0000 & 0.1782 & 0.0710 & 0.1733 \\
\hline & HvSSR12-39 & 289 & ATCTAACAACAACAATCCCG & САTCTTCATCCCTCGTGTAT & 0.8793 & 4.0000 & 0.2211 & 0.1142 & 0.2124 \\
\hline & Mean & & & & 0.7630 & 3.1111 & 0.3346 & 0.1536 & 0.2917 \\
\hline
\end{tabular}

the previous studies on Indian rice varieties [46] and Korean landraces [19].

\section{Hierarchical cluster analysis}

The amplicons generated by HvSSR markers across 729 varieties were used for cluster development using the neighbour joining (NJ) method. The unrooted tree
(Fig. 1) grouped 729 rice varieties into two major clusters, 400 varieties in cluster 1 whereas; 329 varieties were grouped in cluster2. This grouping was further supported by studies of Upadhyaya et al. [46], Nachimuthu et al. [25] and Das et al. [9] who also have reported two clusters during their studies in Indian rice germplasm. Further, we also analyzed clustering pattern of rice 


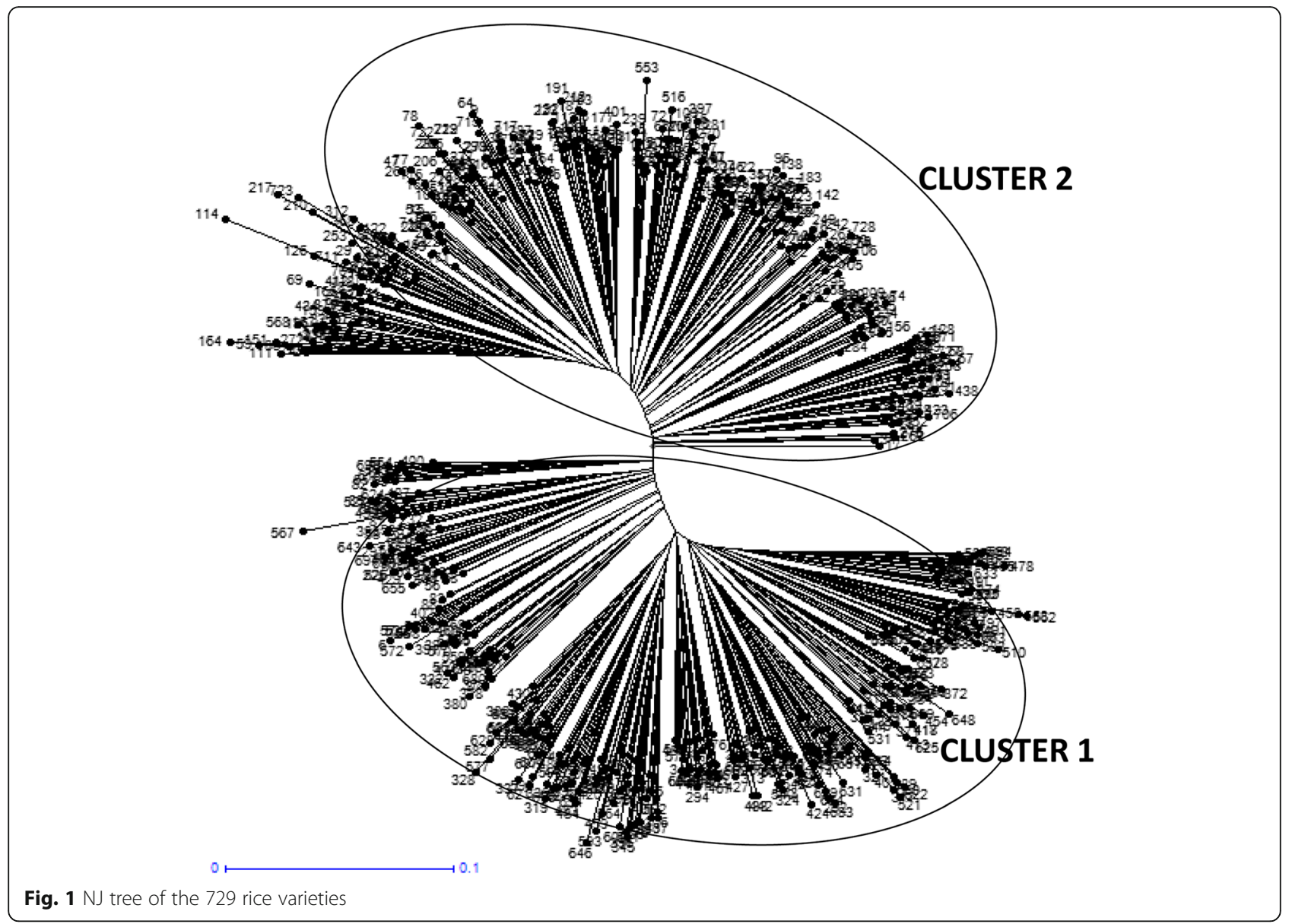

varieties based on their traits. Passport data of some of the varieties contained information about a few key traits which helped us in studying trait based grouping in the NJ clusters. Out of 40 aromatic rice varieties, 25 were grouped into cluster2 and 15 into cluster1. Similarly, out of 15 salt tolerant varieties nine were present in cluster 2 and six were present in the cluster1. This suggests that for the development of aroma and salinity tolerant varieties breeders may have used diverse parents, as reflected by their grouping in both the clusters. Additionally, we also analyzed clustering pattern of hybrids. Interestingly, out of 30 hybrid varieties studied in the set, $22(73.3 \%)$ were grouped into cluster 2 and just eight in cluster1. In cluster1 out of eight hybrids six were having IR series parents common (Additional file 2: Table S2).

\section{Model based population structure}

Population structure divided 729 varieties into 3 populations (Figs. 2 and 3 and Additional file 3: Figure S1). Population1 (pop1), population2 (pop2) and population3 (pop3) contained 72, 329 and 328 varieties, respectively. Further, based on the membership fractions, varieties under different populations were categorized as pure or admixture. The varieties with the probability more than $\geq 0.80$ score was considered as pure and less than 0.80 as

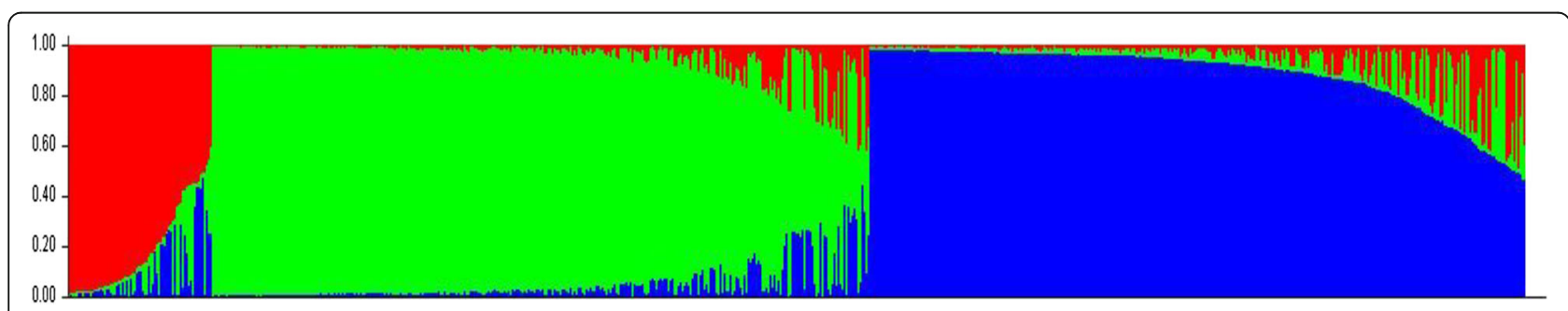

Fig. 2 Population structure of 729 rice varieties 
DeltaK $=\operatorname{mean}\left(\left|\mathrm{L}^{\prime \prime}(\mathrm{K})\right|\right) / \mathrm{sd}(\mathrm{L}(\mathrm{K}))$

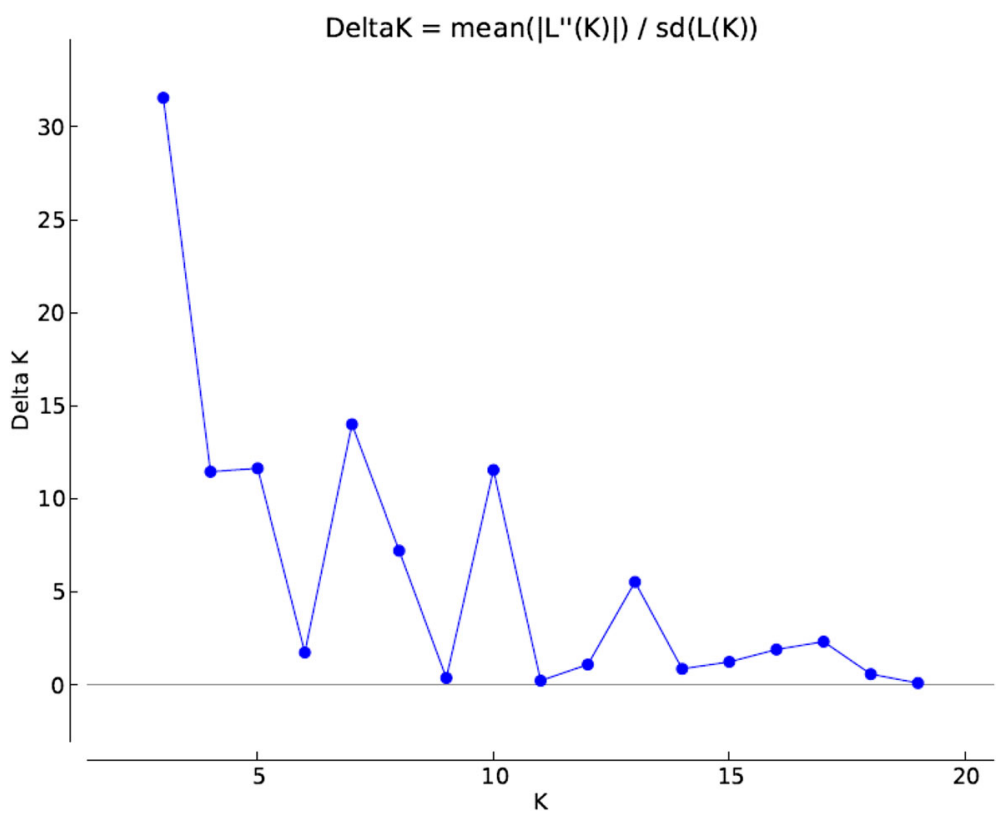

Fig. 3 Estimation of population using $\operatorname{LnP}(\mathrm{D})$ derived $\Delta \mathrm{k}$ for $\mathrm{k}$ from 1 to20

an admixture. Pop1 showed 44 pure (61 \%) and 28 admixed (38 \%) individuals, pop2 showed 282 pure $(86 \%)$ and 47 (14\%) admixed individuals and pop3 showed 260 pure $(79 \%)$ and 68 (20\%) admixed individuals. The mean Fsts value of pop1, pop2 and pop3 were $0.0118,0.3240$ and 0.2667 , respectively, and mean alpha value was 0.0829 (Table 2). The allele frequencies (divergence among populations) were 0.0686 between pop1 and pop2; 0.0533 between pop1 and pop3 and 0.0548 between pop2 and pop3 (Table 3). Earlier studies on population structure have reported two to eight subpopulations using different rice collections $[1,4,13,20$, 49-51]. Roy et al. [36] and Upadhyaya et al. [46] have also reported similar population number in different set of Indian rice varieties. The relatively small value of alpha $(\alpha=0.0829)$ in present study reveals that, only few individuals were admixed. Alpha value approaching zero indicates that most individuals in the study are from separate populations [19] whereas; an alpha value greater than 1 indicates that most of accessions of populations are admixed [28]. Distributions of rice varieties in different populations based on their traits were also studied.

Table 2 Mean value of alpha, Fst1, Fst2 and Fst3 inferred from model based approach

\begin{tabular}{ll}
\hline Mean & Value \\
\hline Mean value of alpha & 0.0829 \\
Mean value of Fst_1 & 0.0118 \\
Mean value of Fst_2 & 0.324 \\
Mean value of Fst_3 & 0.2667 \\
\hline
\end{tabular}

All 30 hybrid varieties and most of the aromatic rice varieties were grouped in pop2 (Fig. 2 and Additional file 3: Figure S1). It was also observed that 190 varieties out of 329 in pop2 were released after 1979, which indicates that most of the recently released varieties were present into pop2. Both hierarchical and model based population structure showed that large number varieties in cluster2 (347) and pop2 (329) correspond to each other.

\section{AMOVA and PCoA of clusters obtained using hierarchical approach}

AMOVA for the 729 varieties was performed based on the two clusters obtained using hierarchical cluster analysis. The two populations showed $3 \%$ variance among themselves, whereas, $61 \%$ variance was recorded among individuals and $36 \%$ variance within individuals (Fig. 4 and Table 4). PCoA based on hierarchical clusters (labeled with two different colours) showed intermixing of two groups across the coordinates (Fig. 5). The first three axes explained $15.9 \%$ of cumulative variation (Table 5).

Table 3 Allele-frequency divergence among populations computed using estimates of P (Model based approach)

\begin{tabular}{llll}
\hline & Pop1 & Pop2 & Pop3 \\
\hline Pop1 & 0 & 0.0686 & 0.0533 \\
Pop2 & 0.0686 & 0 & 0.0548 \\
Pop3 & 0.0533 & 0.0548 & 0 \\
\hline
\end{tabular}




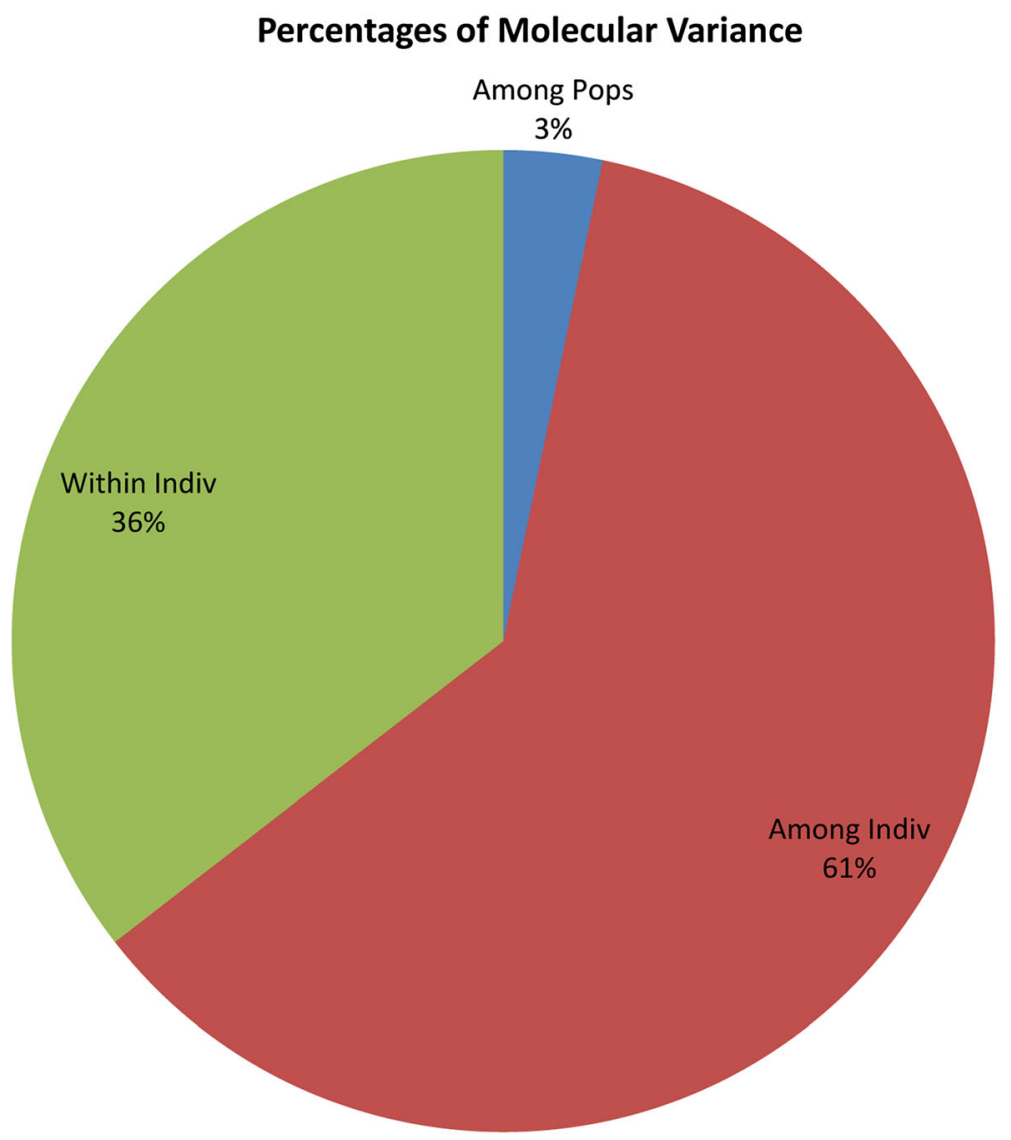

Fig. 4 Analysis of molecular variance (AMOVA) of 729 rice varieties based on populations obtained by hierarchical approach

\section{AMOVA and PCOA of populations obtained using model based approach}

AMOVA was performed on three populations obtained using a model based approach. Among three populations $11 \%$ variance was recorded, whereas, among individuals, $55 \%$ variance and within individuals, $34 \%$ variance was found (Fig. 6 and Table 6). Choudhury et al. [7] have also reported similar pattern of variation in Indian rice germplasm using populations derived from the model based approach. PcoA revealed that large genetic diversity exists in Indian rice varieties. The first three axes explained $15.9 \%$ of cumulative variation (Table 7). In PcoA, rice varieties were labeled with three different colours which represent the three populations obtained from population structure (Fig. 7). The pop1 and pop2 showed

Table 4 Summary of analysis of molecular variance (AMOVA) for hierarchical clustering approach

\begin{tabular}{llrlcl}
\hline Source & Df & \multicolumn{1}{l}{ SS } & MS & Est. Var. & $\%$ \\
\hline Among Pops & 1 & 187.128 & 187.128 & 0.241 & $3 \%$ \\
Among Indiv & 726 & 8517.340 & 11.732 & 4.548 & $61 \%$ \\
Within Indiv & 728 & 1919.000 & 2.636 & 2.636 & $35 \%$ \\
Total & 1455 & 10623.468 & & 7.425 & $100 \%$ \\
\hline
\end{tabular}

distinct grouping whereas; the individuals of pop3 were distributed over pop1 and pop2.

Hierarchical based AMOVA analysis showed less (3\%) variation among population, compared to model based structure population (11\%). The reason for less variation between populations in case of hierarchical clusters may be due to the number of groups predicted (two clusters) which was higher in case of model based approach (three groups).

\section{Decadal genetic diversity trend analysis in Indian rice varieties}

To understand the genetic diversity trend in Indian rice varieties released and notified from 1940 to 2013 an interval of 10-years was taken to keep the number of varieties almost constant in each interval. Except for interval 1940-1965, which was about 26 years, other intervals were about 10 years. Decadal analysis showed a steady increase in gene diversity of varieties released during 1966-1975 (0.314), 1976-1985 (0.315), 19861995 (0.335), 1996-2005 (0.346) but it showed decreasing trend during 2006-2013 (0.290). In contrast to gene diversity, major allele frequency showed decreasing trend in the varieties released during 1940 (0.774) to 


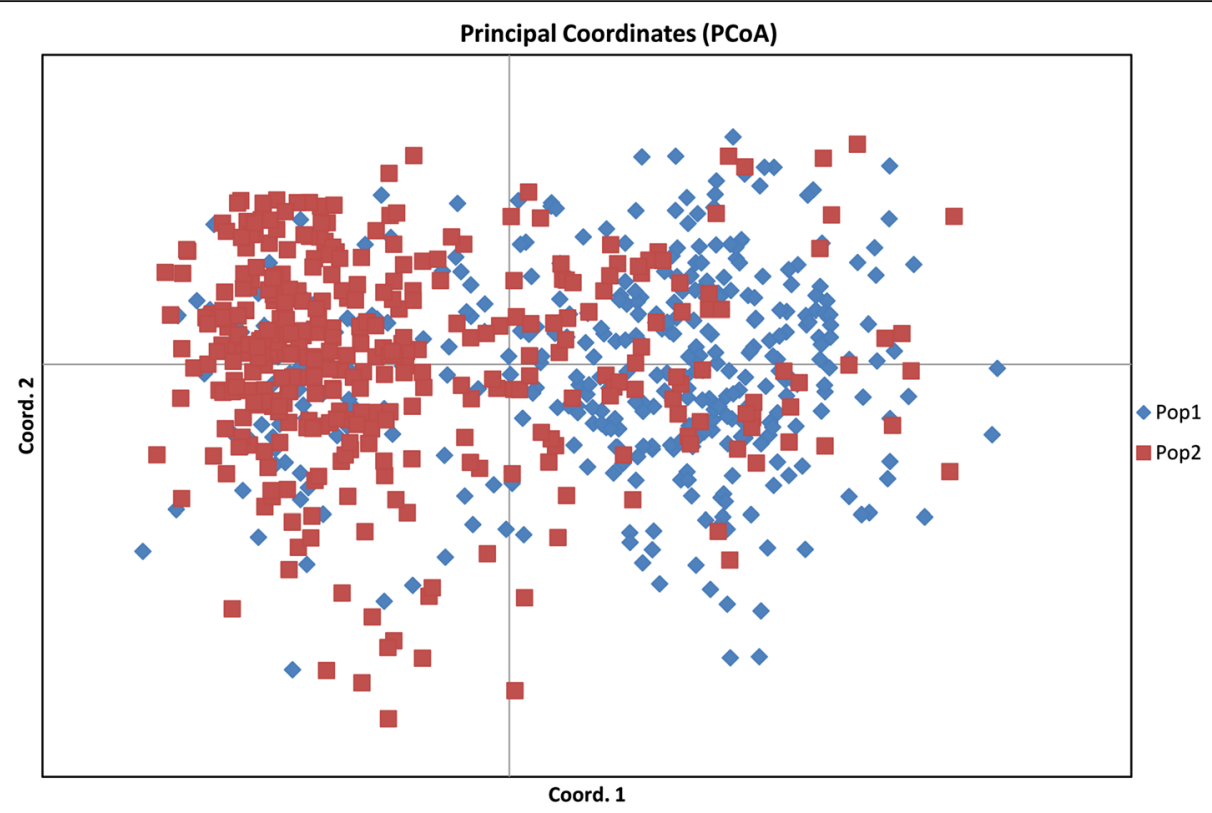

Fig. 5 Principal coordinate analysis (PCOA) of 729 rice varieties based on populations obtained by hierarchical approach

2005 (0.751) whereas; it showed an increase during 2006-2013 (Table 8). Number of alleles (Na) increased remarkably up to $17.3 \%$ in the varieties if we compare the allele number present in the interval 1940-1965 with the allele number present in the interval 1966-1975. But after 1975 , only $3.9 \%$ increase was observed, when interval of 1966-1975 was compared with an interval of 1976-1985 and $1 \%$ increase in the number of alleles was recorded when 1976-1985 interval was compared with 1986-1995. Allele number was constant during 1986-1995 to 1996-2005 interval, but it showed 3 \% increase from interval 1996-2005 to 2006-2013. Similar trends in the number of alleles $(\mathrm{Na})$ was reported by Choudhary et al. [6], whereas; in contrast to this Wei et al. [47] reported decreasing trend in $\mathrm{Na}$ after 1980s using different set of rice collections. Similarly, gene diversity also showed a steady increase in the varieties released during 1940s to 2005, but it decreased in those released during 2006-2013. Mantegazza et al. [23] have reported steady increase in the gene diversity level in Italian rice germplasm; in contrary to this no change was observed in the level of diversity in rice varieties of Nepal [43]. PIC also showed increasing trend in all varieties released over the period of $1940(0.267)$ to 2005

Table 5 Percentage of variation explained by the first 3 axes using Principal coordinate analysis for hierarchical clustering approach

\begin{tabular}{llrr}
\hline Axis & 1 & 2 & \multicolumn{1}{c}{3} \\
\hline$\%$ & 8.08 & 4.14 & 3.66 \\
Cum \% & 8.08 & 12.23 & 15.89 \\
\hline
\end{tabular}

(0.302) whereas; it showed a decrease during 2006-2013 (0.255). Comparison of per cent increase in PIC value showed an increase of $2.27 \%$ between interval 1940 1965 and interval 1966-1975, but no major change was recorded for the interval 1966-1975 and interval 19761985. Further, it showed an increase of $7.13 \%$ and $3.45 \%$ between interval 1976-1985 and 1986-1995 and between intervals 1986-1995 and 1996-2005, respectively. But it drastically decreased (15\%) between $1996-$ 2005 and 2006-2013. It clearly indicates massive loss of genetic diversity in the last 10 years, which may be attributed to shifting towards the trait specific breeding during this period. According to Choudhary et al. [6], the reason for this trend could be the selection priorities of breeders for need based breeding.

\section{Pedigree-based analysis of hierarchical cluster and model based population}

Analysis of varieties sharing common parentage (Additional file 1: Table S1) showed that they were grouped in the same cluster (Fig. 1) or population (Fig. 2). For example, varieties sharing common parentage like CNM-25 and CNM-31, GR11 and GR4, ADT 31 and ADT 33, Kumbham and Makaram were grouped into common cluster2 and pop2. Similarly, Archana and Pusa 4-1-11, KalingaI and KalingaII, Vjaya and Jayanthi were grouped into pop2 and cluster1. Chaitanya and Krishnaveni, Deepti and Nandi, Aruna and Remya, PTB-39 and PTB-41, Sasyasree and Vikas, Moniram, Bahadur, Piolee and Kushal were grouped into pop3 and cluster1, Dharitri and Savitri were grouped into pop3 and cluster2 (Figs. 1 and 2 and Table 9). There were a few exceptions where varieties having common parentage 


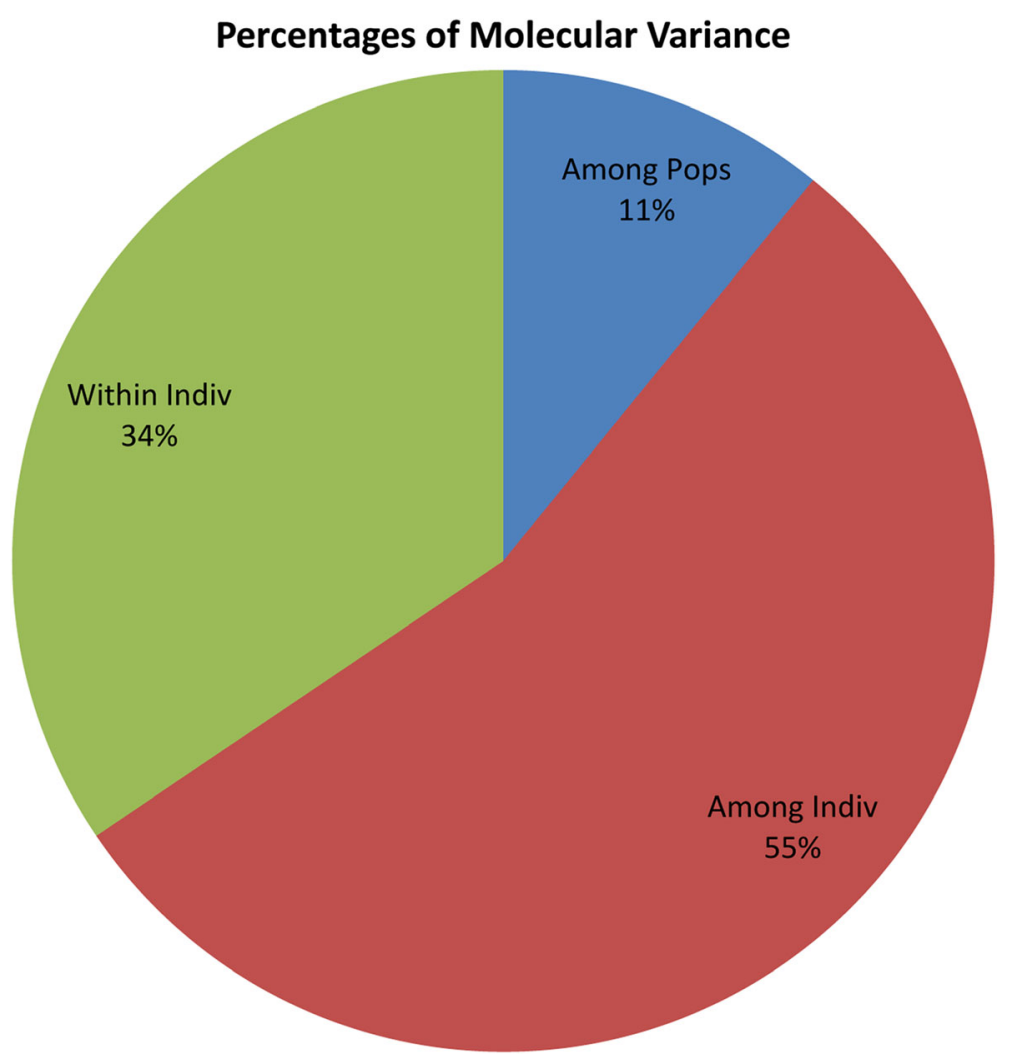

Fig. 6 Analysis of molecular variance (AMOVA) of 729 rice varieties based on population obtained by model based approach

were not grouped together in the same cluster or population. For example, Kanchi and Vaigai were grouped into same population (pop2) but, in different clusters. Similar trend in pedigree based clustering was also observed by Upadhyay et al. $[6,46]$. Upadhyay et al. [46] showed that varieties with at least one common parent were grouped in one cluster and Choudhary et al. [6] showed that varieties released during different decades were also grouped together due to the presence of common parents in their pedigree.

\section{Co-linearity between hierarchical cluster and model based population analysis}

The Co-linearity between varieties grouping in hierarchical cluster and model based population structure was confirmed by Venn diagram. Liu et al. [22] studied the Chinese wild rice collection and has also shown that

Table 6 Summary of analysis of molecular variance (AMOVA) for model based approach

\begin{tabular}{llrlcl}
\hline Source & df & \multicolumn{1}{l}{ SS } & MS & Est. Var. & $\%$ \\
\hline Among Pops & 2 & 729.778 & 364.889 & 0.831 & $11 \%$ \\
Among Indiv & 726 & 7985.068 & 10.999 & 4.182 & $55 \%$ \\
Within Indiv & 729 & 1921.000 & 2.635 & 2.635 & $34 \%$ \\
Total & 1457 & 10635.846 & & 7.648 & $100 \%$ \\
\hline
\end{tabular}

Venn diagram is a robust method to study overlapping accessions. In the Venn diagram out of 729 varieties, 244 rice varieties $(56.5 \%)$ were common between pop2 and cluster2. Similarly, 252 rice varieties $(55.3 \%)$ were common between pop3 and cluster1 (Fig. 8a and b). This study supports that grouping of rice varieties based on hierarchical cluster and model based approach were more than $55 \%$ similar.

\section{Conclusion}

The present study based on 36 HvSSR markers distributed over all 12 chromosomes of rice suggests that after green revolution breeders have used different parentage for improving the yield, quality and plant architecture, but after 2006 priority of breeders have changed and instead of plant architecture, more focus was on breeding for biotic and abiotic stress tolerance and trait-specific improvement. This could be the possible reason that allele number recorded over the period has not decreased,

Table 7 Percentage of variation explained by the first 3 axes using Principal Coordinate analysis for model based approach

\begin{tabular}{llrr}
\hline Axis & 1 & 2 & \multicolumn{1}{c}{3} \\
\hline$\%$ & 8.08 & 4.14 & 3.66 \\
Cum \% & 8.08 & 12.23 & 15.89 \\
\hline
\end{tabular}




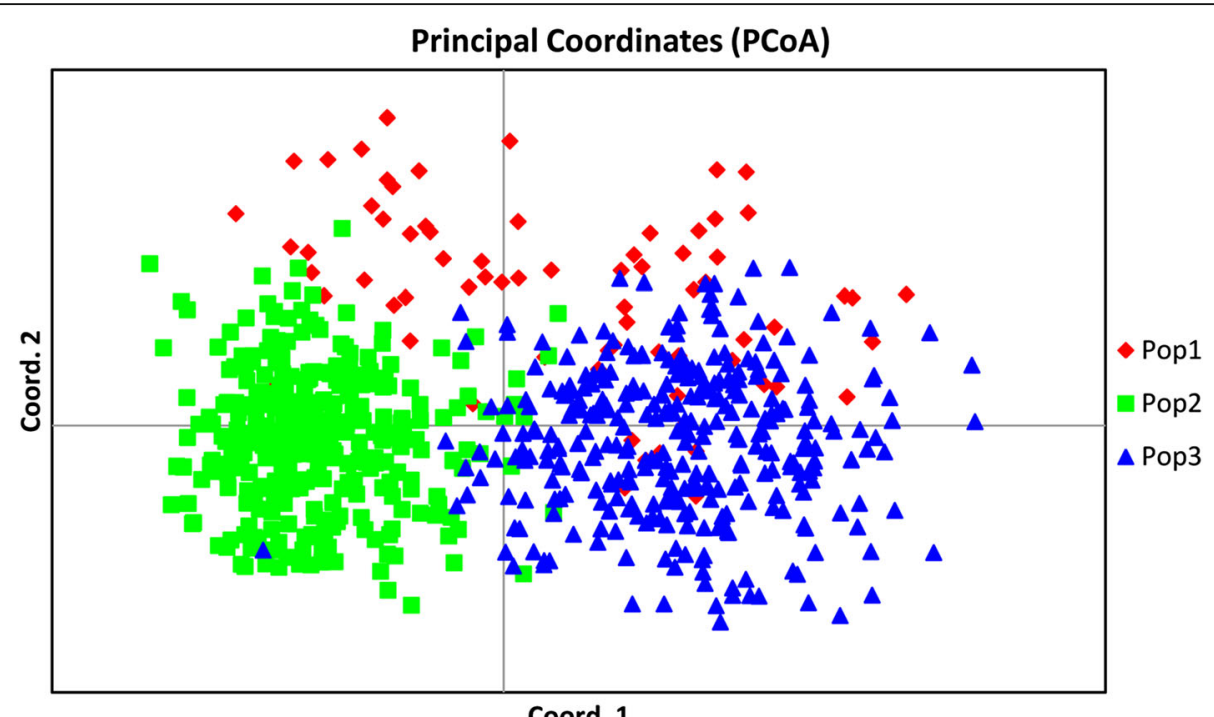

Coord. 1

Fig. 7 Principal coordinate analysis (PCOA) of 729 rice varieties based on population obtained by model based approach

but genetic diversity and PIC have shown a sudden decrease after 2006. To broaden the genetic base, there is an urgent need to incorporate more diverse donor parents in the breeding program for varietal improvement in rice.

\section{Methods}

\section{Plant materials}

Seed samples of 729 varieties of rice received from Indian National Genebank, ICAR- National Bureau of Plant Genetic Resources (NBPGR), New Delhi. The details of each variety along with passport data (National ID, i.e. Indigenous Collection (IC) number, state, local name, pedigree, traits) are given in Additional file 1 : Table S1 [39].

\section{DNA extraction from rice seed}

Seeds of each variety (10-12 seeds) were dehusked and used for DNA isolation using QIAGEN DNeasy plant mini kit (Hilden, Germany). Fine powder was obtained by grinding kernels using tissue lyser (Tissue lyser II Retsch, Germany) with a tissue lyser adapter set (QIAGENq). QIAGEN DNeasy plant mini kit protocol was followed for DNA isolation.
Genotyping of rice varieties using SSR markers

Initial screening was done with 120 highly variable SSR (HvSSR) marker loci with repeat lengths of 51-70 bp which were located across all 12 chromosomes of rice [40]. Finally 36 most polymorphic markers (3markers/ chromosome) were selected, which were covering both long and short arm of rice chromosome for genotyping of 729 rice varieties. Temperature of amplification for each primer was standardized by gradient PCR with selected rice samples.

Working stocks $(10 \mathrm{ng} / \mu \mathrm{l})$ of genomic DNA of all the 729 varieties were prepared. PCR reaction mixture (total volume of $10 \mu \mathrm{l})$ contained $2 \mu \mathrm{l}$ genomic DNA $(10 \mathrm{ng} / \mu \mathrm{l})$, $0.8 \mu \mathrm{l}$ of $25 \mathrm{mM} \mathrm{MgCl}_{2}, 1 \mu \mathrm{l}$ of $10 \mathrm{X}$ buffer, $0.2 \mu \mathrm{l}$ of each primer $(10 \mathrm{nmol}), 0.2 \mu \mathrm{l}$ of $10 \mathrm{mM}$ dNTPs, $0.2 \mu \mathrm{l}$ of Taq DNA polymerase (Fermentas, Life Sciences, USA) and $5.6 \mu \mathrm{l}$ distilled water. The conditions for PCR amplification were as follows: initial denaturation at $94{ }^{\circ} \mathrm{C}$ for 4 min followed by 36 cycles of $94{ }^{\circ} \mathrm{C}$ for $30 \mathrm{~s}$, Ta for $45 \mathrm{~s}$, $72{ }^{\circ} \mathrm{C}$ for $1 \mathrm{~min}$ and final extension at $72{ }^{\circ} \mathrm{C}$ for $10 \mathrm{~min}$. $4 \%$ metaphor agarose gel was used for analyzing the amplified products with the constant supply of $120 \mathrm{~V}$ for $4 \mathrm{~h}$. Gel documentation system (Alpha Imager ${ }^{\circ}$, USA) was used to record the gel pictures.

Table 8 Pattern of gene diversity, heterozygosity, major allele frequency and PIC over decadel periods

\begin{tabular}{|c|c|c|c|c|c|c|}
\hline Intervals & Major allele frequency & Genotype no & Allele no & Gene diversity & Heterozygosity & PIC \\
\hline 1940-1965 & 0.7745 & 2.8056 & 2.4167 & 0.3172 & 0.2000 & 0.2676 \\
\hline 1966-1975 & 0.7835 & 3.7222 & 2.8333 & 0.3148 & 0.1550 & 0.2737 \\
\hline 1976-1985 & 0.7767 & 4.4444 & 2.9444 & 0.3155 & 0.1467 & 0.2732 \\
\hline 1986-1995 & 0.7588 & 4.6667 & 2.9722 & 0.3352 & 0.1390 & 0.2927 \\
\hline 1996-2005 & 0.7515 & 4.5278 & 2.9167 & 0.3468 & 0.1568 & 0.3028 \\
\hline 2006-2013 & 0.8032 & 4.5556 & 3.0000 & 0.2909 & 0.1566 & 0.2553 \\
\hline
\end{tabular}


Table 9 Rice varieties sharing common parentage

\begin{tabular}{|c|c|c|c|c|}
\hline $\begin{array}{l}\text { Name of the } \\
\text { variety }\end{array}$ & $\begin{array}{l}\text { Year of } \\
\text { release/ } \\
\text { notification }\end{array}$ & $\begin{array}{l}\text { Common } \\
\text { parents }\end{array}$ & Cluster & Population \\
\hline CNM-25 & 1980 & \multirow[t]{2}{*}{ IR-8 } & 2 & 2 \\
\hline CNM-31 & 1980 & & 2 & 2 \\
\hline GR-11 & 1977 & \multirow{2}{*}{$\begin{array}{l}\text { Z-31 and } \\
\text { IR-8-246 }\end{array}$} & 2 & 2 \\
\hline GR-4 & 1981 & & 2 & 2 \\
\hline IR-22 & 1978 & \multirow{2}{*}{$\begin{array}{l}\text { IR } 8 \text { and } \\
\text { Tadukan }\end{array}$} & 2 & 2 \\
\hline IR-579 & 1975 & & 2 & 3 \\
\hline ADT 31 & 1975 & \multirow{2}{*}{$\begin{array}{l}\text { IR } 8 \text { and } \\
\text { Cul. } 340\end{array}$} & 2 & 2 \\
\hline ADT 33 & 1979 & & 2 & 2 \\
\hline Kanchi & 1970 & \multirow{2}{*}{$\begin{array}{l}\text { TN } 1 \text { and } \\
\text { CO } 29\end{array}$} & 2 & 2 \\
\hline Vaigai CO 37 & 1974 & & 1 & 2 \\
\hline Kumbham (KTR- 3) & 1998 & \multirow[t]{2}{*}{ Cherady } & 2 & 2 \\
\hline Makaram (KTR- 2) & 1998 & & 2 & 2 \\
\hline Archana & 1974 & \multirow{2}{*}{$\begin{array}{l}\text { IR8 and } \\
\text { Tadukan }\end{array}$} & 1 & 2 \\
\hline Pusa - 4-1- 11 & & & 1 & 2 \\
\hline Kalinga II & 1973 & \multirow{2}{*}{$\begin{array}{l}\text { Dunghansalia } \\
\text { and IR8 }\end{array}$} & 1 & 2 \\
\hline Kalinga I & 1973 & & 1 & 2 \\
\hline Vijaya & 1970 & \multirow[t]{2}{*}{ T90 and IR8 } & 1 & 2 \\
\hline $\begin{array}{l}\text { Jayanthi } \\
\text { (AC-30919) }\end{array}$ & 1973 & & 1 & 2 \\
\hline Chaitanya & 1989 & \multirow{2}{*}{$\begin{array}{l}\text { Sowbhagya } \\
\text { and ARC } 5984\end{array}$} & 1 & 3 \\
\hline Krishnaveni & 1990 & & 1 & 3 \\
\hline Nandi (MTU-5182) & 1993 & \multirow{2}{*}{$\begin{array}{l}\text { Sowbhagya } \\
\text { and ARC-6650 }\end{array}$} & 1 & 3 \\
\hline Deepti (MTU-4870) & 1997 & & 1 & 3 \\
\hline Aruna (MO-8) & 1989 & \multirow{2}{*}{$\begin{array}{l}\text { Jaya and } \\
\text { PTB } 33\end{array}$} & 1 & 3 \\
\hline Remya (MO-10) & 1989 & & 1 & 3 \\
\hline PTB-39 & 1972 & \multirow{2}{*}{$\begin{array}{l}\text { PTB } 10 \text { and } \\
\text { IR-8 }\end{array}$} & 1 & 3 \\
\hline PTB-41 & 1972 & & 1 & 3 \\
\hline $\begin{array}{l}\text { Krishna Anjana } \\
\text { (MO-19) }\end{array}$ & 2002 & \multirow[t]{2}{*}{$\begin{array}{l}\text { MO-1 and } \\
\text { MO-6 }\end{array}$} & 1 & 3 \\
\hline Karishma (MO-18) & 1998 & & 1 & 1 \\
\hline Moniram & 1991 & \multirow{5}{*}{$\begin{array}{l}\text { Pankaj and } \\
\text { Mahsuri }\end{array}$} & 1 & 3 \\
\hline Piolee & 1991 & & 1 & 3 \\
\hline Bahadur & 1994 & & 1 & 3 \\
\hline Kushal & 1994 & & 1 & 3 \\
\hline Ranjit & 1994 & & 2 & 3 \\
\hline Ratna & 1970 & \multirow{3}{*}{$\begin{array}{l}\text { TKM-6 and } \\
\text { IR-8 }\end{array}$} & 1 & 3 \\
\hline Sasya Sree & 1980 & & 1 & 3 \\
\hline Vikas & 1983 & & 1 & 3 \\
\hline Dharitiri & 1989 & \multirow{2}{*}{$\begin{array}{l}\text { Pankaj and } \\
\text { Jagannath }\end{array}$} & 2 & 3 \\
\hline Savitri (Ponmani) & 1983 & & 2 & 3 \\
\hline
\end{tabular}

\section{Statistical analyses}

Power Marker 3.5 [21] was used to calculate major allele frequency, gene diversity, heterozygosity and polymorphic

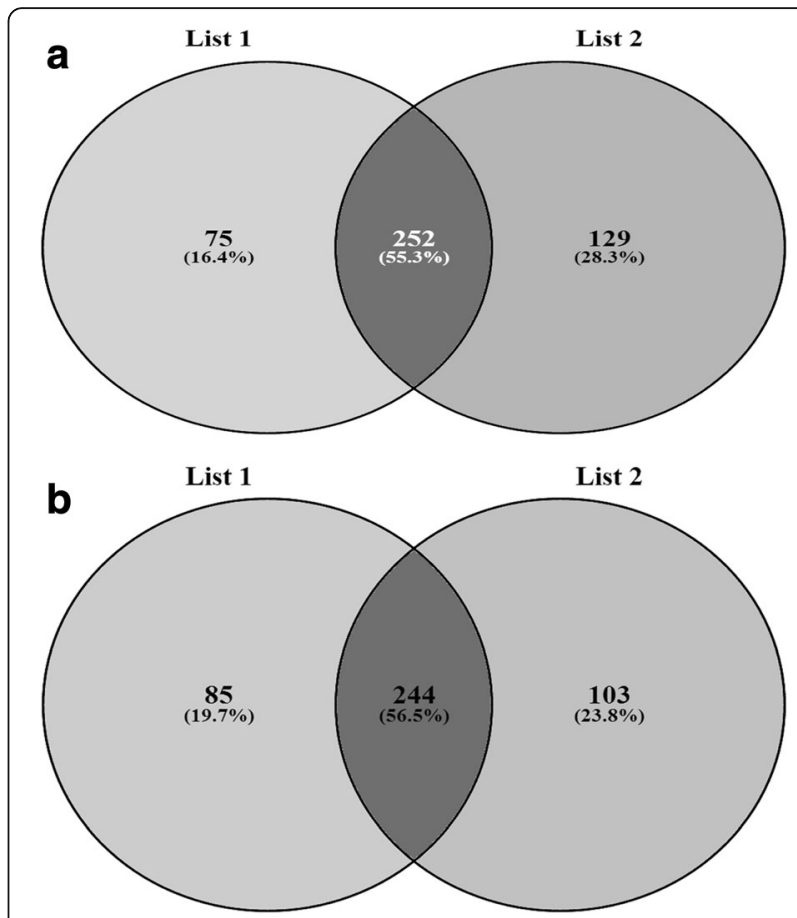

Fig. 8 a Venn diagram showing co linearity between population 2 \& cluster 2. b Venn diagram showing co linearity between population3 \& cluster1

information content (PIC) for each locus of HvSSR markers. The genetic distance calculated for each variety with Power marker, which was used for cluster development using neighbor-joining (NJ) tree. The un-weighted neighbor joining tree was constructed using DARwin software 5.0.158 [32] GenAlEx V6.5 [31] was used to study PCoA and AMOVA. To study the population structure model-based program, STRUCTURE 2.3.3 [34] was used and three replications were run for each $\mathrm{K}$. Each run was implemented with a burn-in period of 100,000 steps with 100,000 Monte Carlo Markov Chain replicates [34]. The membership of each genotype was run for a range of genetic clusters from value of $\mathrm{K}=1$ to 20 by taking the admixture model and correlated allele frequency into account. The plateau of $\Delta \mathrm{K}$ was obtained by plotting LnPD values derived for each K [11]. The final population was determined using "Structure harvester" program (http://taylor0.biology.ucla.edu/ structureHarvester/). Venn diagram analysis was performed to identify common varieties between cluster and population using software Venny 2.1 [27].

\section{Ten-year interval analysis}

All 729 rice varieties were divided into six different intervals on the basis of year of release and notification [1940-1965 (18 varieties), 1966-1975 (69), 1976-1985 (127), 1986-1995 (168), 1996-2005 (147), and 20062013 (136)]. Except 1940-1965, all intervals showed approximately comparable number of genotypes. The 

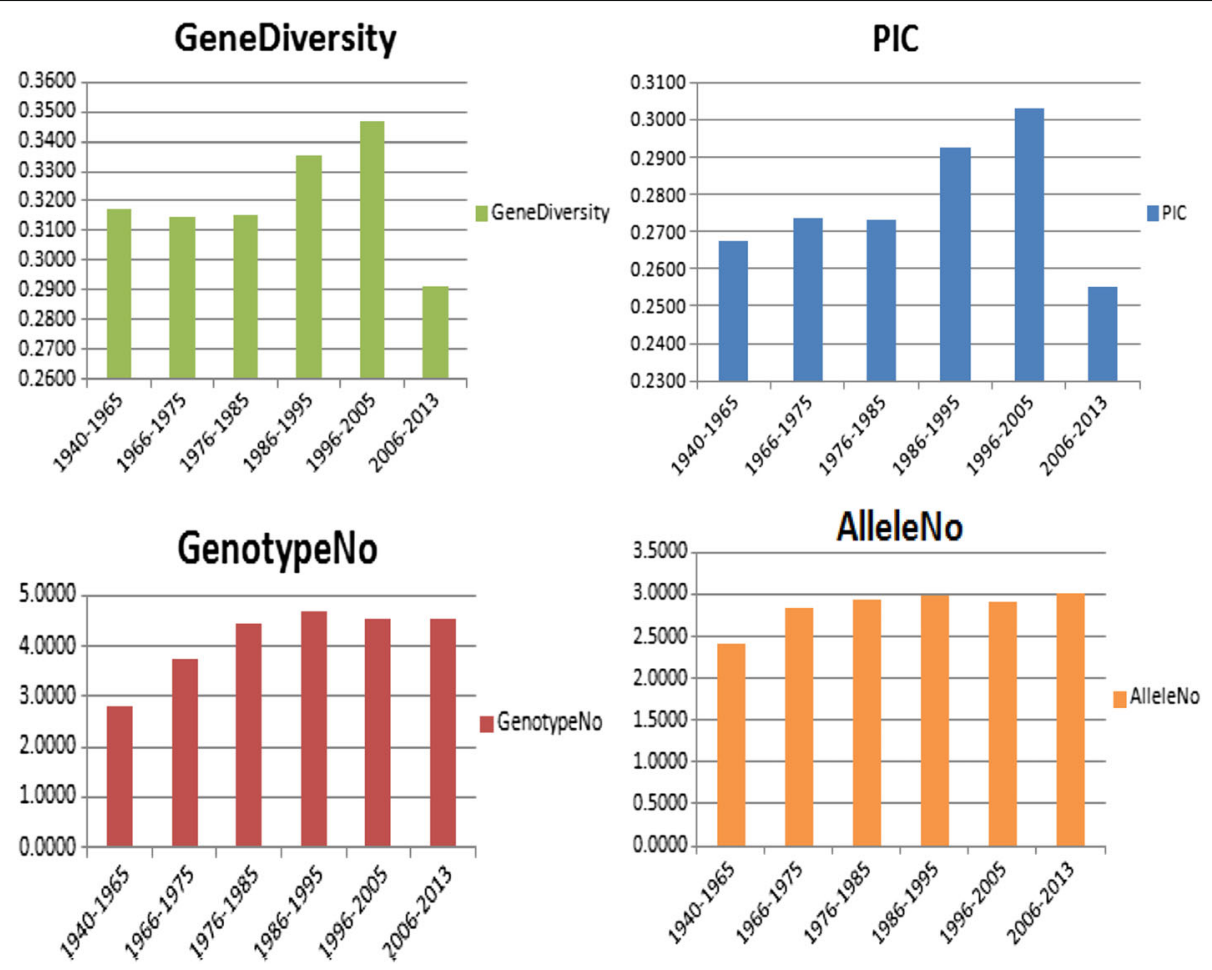

Fig. 9 Graphs showing gene diversity, PIC, genotype no and allele number of the 729 rice varieties

value of gene diversity, heterozygosity, major allele frequency and PIC of rice varieties falling in six time intervals were analyzed using the Power Marker. The mean value of gene diversity, heterozygosity, major allele frequency and PIC were plotted with years (time interval) on $\mathrm{X}$ axis and values of gene diversity, heterozygosity, major allele frequency and PIC on Y axis (Fig. 9).

\section{Additional files}

Additional file 1: Table S1. List of rice varieties characterized using HVSSR markers along with their pedigree, IC number, year of release and traits. (XLSX $79 \mathrm{~kb})$

Additional file 2: Table S2. List of hybrid rice used in the present study with year of release and pedigree. (XLSX $10 \mathrm{~kb}$ )

Additional file 3: Figure S1. Detailed population structure of 729 rice varieties based on SSR data. (PDF $459 \mathrm{~kb}$ )

\section{Acknowledgement}

We are thankful to the Director, NBPGR, New Delhi, who provided facilities for this work.

\section{Funding}

Financial supports granted by Indian Council of Agricultural Research (ICAR), New Delhi, India, under project PGR/GRD-BUR-DEL-01.02 [IXX10476] and NPTC project are gratefully acknowledged. The funder has no role in the design of the study and collection, analysis, and interpretation of data and in writing the manuscript.

\section{Availability of data and materials}

The datasets supporting the results of this article are included within the article and its additional files.

\section{Authors' contributions}

RS and NKS Conceived and designed the experiments, DRC, NS and GT Performed the experiments, RS, DRC, AKS and SK Analyzed the data, KS, RKT and ADS Contributed reagents/materials/analysis tools, RS, NS, AKS and RKT Contributed to the writing of the manuscript. All authors have read and approved the final manuscript.

\section{Competing interests}

The authors declare that they have no competing interests.

\section{Consent for publication}

Not applicable.

\section{Ethics approval and consent to participate}

Not applicable.

\section{Author details}

${ }^{1}$ Division of Genomic Resources, ICAR-National Bureau of Plant Genetic Resources, New Delhi 110 012, India. ${ }^{2}$ Division of Germplasm Conservation, ICAR-National Bureau of Plant Genetic Resources, New Delhi 110 012, India. ${ }^{3}$ ICAR-National Research Centre on Plant Biotechnology, Pusa Campus, IARI, New Delhi 110012, India.

Received: 29 April 2016 Accepted: 30 August 2016

Published online: 05 September 2016

\section{References}

1. Agrama H, Eizenga G, Yan W. Association mapping of yield and its components in rice cultivars. Mol Breed. 2007;19(4):341-56.

2. Anand D, Prabhu KV, Singh AK. Analysis of molecular diversity and fingerprinting of commercially grown Indian rice hybrids. J Plant Biochem Biotechnol. 2012;21(2):173-79.

3. Babu BK, Meena V, Agarwal V, Agrawal PK. Population structure and genetic diversity analysis of Indian and exotic rice (Oryza sativa L.) accessions using SSR markers. Mol Biol Rep. 2014;41(7):4328-39. 
4. Chakhonkaen S, Pitnjam K, Saisuk W, Ukoskit K, Muangprom A. Genetic structure of Thai rice and rice accessions obtained from the internationa rice research institute. Rice. 2012;5(1):19-32.

5. Choudhury DR, Singh N, Singh AK, Kumar S, Srinivasan K, Tyagi RK, et al. Analysis of genetic diversity and population structure of rice germplasm from North-eastern region of India and development of a core germplasm set. PLoS One. 2014;9(11), e113094.

6. Choudhary G, Ranjitkumar N, Surapaneni M, Deborah DA, Vipparla A, Anuradha $G$, et al. Molecular genetic diversity of major Indian rice cultivars over decadal period. PLoS One. 2013;8(6), e66197.

7. Choudhury B, Khan ML, Dayanandan S. Genetic structure and diversity of indegenous rice (Oryza sativa) varieties in the Eastern Himalyan region of Northeast India. Springer Plus. 2013;2(1):228-38.

8. Christiansen MJ, Andersen SB, Ortiz R. Diversity changes in an intensively bred wheat germplasm during the 20th century. Mol Breed. 2002;9(1):1-11.

9. Das B, Sengupta S, Parida SK, Roy B, Ghosh M, Prasad M, et al. Genetic diversity and population structure of rice landraces from Eastern and North Eastern States of India. BMC Genet. 2013;14(1):71. doi:10.1186/ 1471-2156-14-71.

10. Dudley JW. Plant breeding- a vital part of improvement in crop yields, quality and production efficiency. In: Frey KJ, editor. Historical perspectives in plant sciences. Ames: lowa State University Press; 1994. p. 163-77.

11. Evano G, Regnuat S, Goudet J. Detecting the number of clusters of individuals using the software STRUCTURE: a simulation study. Mol Ecol. 2005;14:2611-20.

12. Fu Y-B, Peterson GW, Yu J-K, Gao L, Jia J, Richards KW. Impact of plant breeding on genetic diversity of the Canadian hard red spring wheat germplasm as revealed by EST-derived SSR markers. Theor Appl Genet. 2006;112(1):1239-47

13. Garris AJ, Tai TH, Coburn J, Kresovich S, McCouch S. Genetic structure and diversity in Oryza sativa L. Genetics. 2005;169(3):1631-38.

14. Heal G, Walker B, Levin S, Arrow K, Dasgupta P, Dailyd G, et al. Genetic diversity and interdependent crop choices in agriculture. Resour Energy Econ. 2004;26:175-84.

15. Huang X-Q, Wolf M, Ganal MW, Orford S, Koebner RMD, Roder MS. Did modern plant breeding lead to genetic erosion in European winter wheat varieties? Crop Sci. 2007:47:343-49.

16. Hysing S-C, Sa"lla T, Nybom H, Liljeroth E, Merker A, Orforda S, et al. Temporal diversity changes among 198 Nordic bread wheat landraces and cultivars detected by retrotransposon-based S-SAP analysis. Plant Genet Resour. 2008;6(2):113-25.

17. Jin L, Lu Y, Xiao P, Sun M, Corke H, Bao J. Genetic diversity and population structure of a diverse set of rice germplasm for association mapping. Theor Appl Genet. 2010;121(3):475-87.

18. Kibria K, Nur F, Begum SN, Islam MM, Paul SK, Rahman KS. Molecular marker based genetic diversity analysis in aromatic rice genotypes using SSR and RAPD markers. Int J Sustain Crop Prod. 2009;4(1):23-34

19. Li FP, Lee YS, Kwon SW, Li G, Park YJ. Analysis of genetic diversity and trait correlations among Korean landrace rice (Oryza sativa L.). Genet Mol Res. 2014;13(3):6316-31.

20. Liakat Ali M, McClung AM, Jia MH, Kimball JA, McCouch SR, Georgia CE. A rice diversity panel evaluated for genetic and agro-morphological diversity between subpopulations and its geographic distribution. Crop Sci. 2011;51(5):2021-35.

21. Liu K, Muse SV. Power Marker: an integrated analysis environment for genetic marker analysis. Bioinformatics. 2005;21(9):2128-29.

22. Liu W, Shahid MQ, Bai L, Lu Z, Chen Y, Jiang L, et al. Evaluation of genetic diversity and development of a core collection of wild rice (Oryza rufipogon Griff.) Populations in China. PLoS One. 2015;10(12), e0145990

23. Mantegazza R, Biloni M, Grassi F, Basso B, Lu B-R, Cai XX, et al. Temporal trends of variation in Italian rice germplasm over the past two centuries revealed by AFLP and SSR Markers. Crop Sci. 2008;48:1832-40.

24. McCouch SR, Chen X, Panaud O, Temnykh S, Xu Y, Cho YG, et al. Microsatellite marker development, mapping and applications in rice genetics and breeding. Plant Mol Biol. 1997;35(1-2):89-99.

25. Nachimuthu W, Muthurajan R, Duraialaguraja S, Sivakami R, Pandian BA, Ponniah G, et al. Analysis of population structure and genetic diversity in rice germplasm using SSR Markers: An initiative towards association mapping of agronomic traits in Oryza sativa. Rice. 2015;8: $30-54$.
26. Neeraja CN, Vemireddy LR, Malathi S, Siddiq EA, et al. Identification of alternate dwarfing gene sources to widely used Dee-Gee-Woo-Gen allele of sd1 gene by molecular and biochemical assays in rice (Oryza sativa L.). Electronic J Biotechn. 2009;12(3):1-11.

27. Oliveros JC. Venny. An interactive tool for comparing lists with Venn's diagrams. 2007-2015. http://bioinfogp.cnb.csic.es/tools/venny/index.html. Accessed 1 Feb 2016.

28. Ostrowski MF, David J, Santoni S, McKhann H, Reboud X, Corre VL, et al. Evidence for a large-scale population structure among accessions of Arabidopsis thaliana: possible causes and consequences for the distribution of linkage disequilibrium. Mol Ecol. 2006;15(6):1507-17.

29. Pachauri V, Taneja N, Vikram P, Singh NK, Singh S. Molecular and morphological characterisation of Indian farmers rice varieties (Oryza sativa L.). AJCS. 2013;7(7):923-32.

30. Pal S, Jain S, Saini N, Aarti, Jain RK. Identification of microsatellite markers for differentiating some Basmati and non- Basmati varieties. IJBT. 2004;3(4):519-26.

31. Peakall R, Smouse P. GenAlEx 6.5: Genetic analysis in Excel. Population genetic software for teaching and research - an update. Bioinformatics. 2012;28(19):2537-39.

32. Perrier $X$, Jacquemoud-Collet JP. DARwin software. 2006. http://darwin.cirad. fr/. Accessed 30 Sept 2015.

33. Plucknett DL, Smith NJH, Williams JT, Anishetty NM. Gene banks and the world's food. Princeton, New Jersey: Princeton University Press; 1987. p. 247

34. Pritchard JK, Stephens M, Donnelly P. Inference of population structure using multilocus genotype data. Genetics. 2000;155(2):945-59.

35. Roussel V, Koenig J, Beckert M, Balfourier F. Molecular diversity in French bread wheat accessions related to temporal trends and breeding programmes. Theor Appl Genet. 2004;108(5):920-30.

36. Roy S, Banerjee A, Mawkhlieng B, Misra AK, Pattanayak A, Harish GD, et al. Genetic diversity and population structure in aromatic and quality rice (Oryza sativa L.) landraces from North-Eastern India. PloS One. 2015;10(6), e0129607.

37. Salgotra RK, Gupta BB, Bhat JA, Sharma S. Genetic diversity and population structure of Basmati rice (Oryza sativa L.) germplasm collected from North Western Himalayas using trait linked SSR markers. PLoS One. 2015;10(7): e0131858.

38. Shah SM, Naveed SA, Arif M. Genetic diversity in Basmati and nonBasmati rice varieties based on microsatellite markers. Pak J Bot. 2013; 45:423-31.

39. Shobha Rani N, Srikanth $S$, Bhadana VP, Jyothi B, Sundaram RM, Senguttuvel P, Prasad GSV, Trushar S, Prasad PVNS, Hari Prasad AS, Subba Rao LV, Agarawal SK, Viraktamath BC. Genetic diversity and genealogy of rice varieties of India. Hyderabad: Directorate of Rice research (ICAR); 2014 p. 368. Technical Book No: 83/2014.

40. Singh H, Deshmukh RK, Singh A, Singh AK, Gaikwad K, Sharma TR, et al. Highly variable SSR markers suitable for rice genotyping using agarose gels. Mol Breed. 2010;25(2):359-64.

41. Singh KN, Nandi R, Shanmugasundram P, Sadasivam S, Huang N, Brar DS, et al. High-resolution DNA fingerprinting of Indian rice (Oryza sativa $\mathrm{L}$ ) varieties by amplified fragment length polymorphism. Genet Resour Crop Evol. 1999;46(5):427-33.

42. Sivaranjani AKP, Pandey MK, Sudharshan I, Kumar GR, Madhav MS, Sundaram RM, et al. Assessment of genetic diversity among Basmati and non-Basmati aromatic rices of India using SSR markers. Current Sci. 2010; 99(2):221-26

43. Steele KA, Gyawali S, Joshi KD, Shrestha P, Sthapit BR, Witcombe JR. Has the introduction of modern rice varieties changed rice genetic diversity in a high altitude region of Nepal? Field Crops Res. 2009;113(1):24-30.

44. Sow M, Ndjiondjop M-N, Sido A, Mariac C, Laing M, Bezançon G. Genetic diversity, population structure and differentiation of rice species from Niger and their potential for rice genetic resources conservation and enhancement. Genet Resour Crop Evol. 2014;61(1):199-13.

45. Upadhyay P, Singh VK, Neeraja CN. Identification of genotype specific alleles and molecular diversity assessment of popular rice (Oryza sativa L.) varieties of India. Int J Plant Breed Genet. 2011;5(2):130-40.

46. Upadhyay P, Neeraja CN, Kole C, Singh VK. Population structure and genetic diversity in popular rice varieties of India as evidenced from SSR analysis. Biochem Genet. 2012;50(9-10):770-83.

47. Wei X, Yuan X, Yu H, Wang Y, Xu Q, Tang S. Temporal changes in SSR allelic diversity of major rice cultivars in China. J Genet Genomics. 2009; 36(6):363-70. 
48. White J, Law JR, MacKay I, Chalmers KJ, Smith JS, Kilian A, et al. The genetic diversity of UK, US and Australian cultivars of Triticum aestivum measured by DArT markers and considered by genome. Theor Appl Genet. 2007; 116(3):439-53.

49. Zhang D, Zhang H, Wang M, Sun J, Qi Y, Wang F, et al. Genetic structure and differentiation of Oryza sativa L. in China revealed by microsatellites. Theor Appl Genet. 2009;119(6):1105-17.

50. Zhang D, Zhang H, Wei X, Qi Y, Wang M, Sun J, et al. Genetic structure and diversity of Oryza sativa L. in Guizhou, China. Chinese Sci Bull. 2007;52(3): 343-51.

51. Zhang P, Li J, Li X, Liu X, Zhao X, Lu Y. Population structure and genetic diversity in a rice core collection (Oryza sativa L.) investigated with SSR markers. PLoS One. 2011;6(12):e27565.

Submit your next manuscript to BioMed Central and we will help you at every step:

- We accept pre-submission inquiries

- Our selector tool helps you to find the most relevant journal

- We provide round the clock customer support

- Convenient online submission

- Thorough peer review

- Inclusion in PubMed and all major indexing services

- Maximum visibility for your research

Submit your manuscript at www.biomedcentral.com/submit
Biomed Central 